\title{
BMJ Open How do women trade-off benefits and risks in chemotherapy treatment decisions based on gene expression profiling for early-stage breast cancer? A discrete choice experiment
}

\author{
Deborah A Marshall, ${ }^{1}$ Ken Deal, ${ }^{2}$ Yvonne Bombard, ${ }^{3,4}$ Natasha Leighl, ${ }^{5,6}$ \\ Karen $\mathrm{V}$ MacDonald, ${ }^{1}$ Maureen Trudeau ${ }^{7,8}$
}

To cite: Marshall DA, Deal K, Bombard $Y$, et al. How do women trade-off benefits and risks in chemotherapy treatment decisions based on gene expression profiling for early-stage breast cancer? A discrete choice experiment. BMJ Open 2016;6:e010981. doi:10.1136/bmjopen-2015010981

- Prepublication history and additional material is available. To view please visit the journal (http://dx.doi.org/ 10.1136/bmjopen-2015010981).

Received 24 December 2015 Revised 1 March 2016 Accepted 30 March 2016

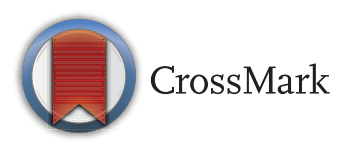

For numbered affiliations see end of article.

Correspondence to Deborah A Marshall; damarsha@ucalgary.ca

\section{ABSTRACT}

Objectives: Gene expression profiling (GEP) of tumours informs baseline risk prediction, potentially affecting adjuvant chemotherapy decisions for women with early-stage breast cancer. Since only $15 \%$ will experience a recurrence, concerns have been raised about potential harms from overtreatment and high GEP costs in publicly funded healthcare systems. We aimed to estimate preferences and personal utility of GEP testing information and benefit-risk trade-offs in chemotherapy treatment decisions.

Design, setting and intervention: Based on literature review and findings from our qualitative research (focus groups, interviews with patients with breast cancer and medical oncologists), we developed a discrete choice experiment (DCE) survey and administered it via an internet panel. The DCE included 12 choice tasks with 5 attributes and 3 alternatives considering orthogonality, D-efficiency and level balance.

Participants: The DCE survey was administered to 1004 Canadian women from the general population.

Main outcome measures: Preferences were analysed using conditional logit and hierarchical Bayes and evaluated for goodness of fit. We conducted simulation analyses for alternative scenarios.

Results: GEP test score indicating likely benefit from chemotherapy was the most important attribute. Doctor's clinical estimate of the risk of cancer returning, trust in your cancer doctor and side effects of chemotherapy (temporary and permanent) were relatively less important but showed significant differences among levels. In the scenario analyses, $78 \%$ were likely to choose chemotherapy in a high-risk scenario, $55 \%$ in a moderate-risk scenario and $33 \%$ in a low-risk scenario, with the other attributes held constant. A high GEP score was more important in influencing the choice of chemotherapy for those at intermediate clinical risk.

Conclusions: GEP testing information influences chemotherapy treatment decisions in early-stage breast cancer and varies depending on clinical risk. Clinicians should be aware of these differences and tailor the use of GEP testing accordingly.
Strengths and limitations of this study

- The first utility-based survey to obtain quantitative benefit-risk data on the value of gene expression profiling (GEP) in breast cancer treatment decisions.

- The hypothetical choice tasks had high face validity, demonstrated by the directionality, magnitude and consistency of responses, and high rate of confirmation about chemotherapy decisions.

- Large sample of women from the general population who may be at risk of breast cancer and are major stakeholders in a publicly funded healthcare system.

- Possibility of incentive bias when using an online survey panel.

- The choice tasks were hypothetical scenarios, and respondents' choices may be different when faced with these decisions in real life.

\section{INTRODUCTION}

Breast cancer is the most common form of cancer in women in North America. ${ }^{1}{ }^{2}$ Women with early-stage breast cancer are faced with challenging treatment decisions that require balancing risks and benefits. Current guidelines suggest that women with human epidermal growth factor receptor 2 (HER2)-negative, oestrogen receptor-positive, lymph node-negative cancer should be offered adjuvant chemotherapy. ${ }^{3-6}$ However, it is estimated that only $15 \%$ of these cancers will recur. ${ }^{3-6}$ As a result, some patients may be treated without benefit but are at risk of side effects from chemotherapy, and the associated treatment costs are borne by patients, caregivers and the healthcare system.

In recent years, concerns have been raised regarding overdiagnosis and overtreatment which can be harmful to patients' health and increase burden on the healthcare system. ${ }^{78}$ Cultural beliefs that more treatment is 
better, ${ }^{9}$ as well as fear and uncertainty for patients and doctors may contribute to disease overtreatment. ${ }^{10}$ It is increasingly important to understand how individuals weigh the benefits and risks of treatment alternatives.

Gene expression profiling (GEP; eg, Oncotype DX), a form of personalised medicine, predicts the likelihood of cancer recurrence and can help identify women who may not benefit from chemotherapy, sparing them from associated toxicity. ${ }^{11-15}$ GEP is increasingly used in clinical practice to support clinical decisions by oncologists and is specified in treatment guidelines as a complement or replacement to clinical algorithms that inform treatment decisions. ${ }^{61617}$ Several studies have examined how receiving GEP results changes chemotherapy treatment decisions by women with breast cancer and their oncologists. $^{18-26}$ However, it remains unclear how women value GEP when weighing the benefits and risks in chemotherapy decisions.

Although attitude surveys provide important information, preference studies require respondents to trade-off risks and benefits of treatment or testing, which allows for a quantification of preferences as a measure of personal utility (the meaning and worth an individual gives to a genomic or genetic test from their personal perspective) ${ }^{27}{ }^{28} \mathrm{~A}$ common method for measuring preferences is using a discrete choice experiment (DCE), in which respondents evaluate alternative scenarios and the relative importance of specific attributes in each scenario. ${ }^{29}$ DCEs have been recommended as a method to measure personal utility in the area of genetics and genomics. ${ }^{30} 31$

Without evidence of GEP's value for informing treatment decisions, it is unclear whether or not it should be supported and reimbursed through a publicly funded healthcare system. Given the considerable cost of GEP, $\sim$ US $\$ 4000$, the value of testing needs to be considered in the context of allocating limited healthcare resources where public values are increasingly incorporated into policy decisions. ${ }^{32}$ To our knowledge, no studies have measured preferences and the personal utility of GEP for informing chemotherapy decisions in early-stage breast cancer using utility-based methods. We aimed to estimate preferences and the personal utility of GEP testing information in chemotherapy decisions based on benefit-risk trade-offs using a DCE.

\section{METHODS}

\section{Study sample}

We administered a DCE survey online to a sample of Canadian women (18 years and older) from the general population, recruited through an internet-based survey panel (Research Now). Age, education and province of residence quotas were set to ensure the sampled population was representative of the Canadian population. Research Now recruits panel members by invitation only, which yields high level of panel quality and representativeness, guards against duplication, fraudulent respondents and professional survey takers. ${ }^{33}$
We estimated our minimum required sample size using the following calculation based on the number of choice tasks, attributes and levels: $\left(\mathrm{N}_{\text {resp }} \times \mathrm{N}_{\text {scen }}\right) /$ $\mathrm{N}_{\text {att }}>500,{ }^{34} 35$ where $\mathrm{N}_{\text {resp }}$ is the number of respondents, $\mathrm{N}_{\text {scen }}$ is the number of choice tasks each respondent completes and $\mathrm{N}_{\mathrm{att}}$ is the maximum number of levels for any single attribute. In our DCE survey, there were 10 random choice tasks and the maximum number of attribute levels was 4 . As such, the minimum sample size required was $n=200$ respondents to achieve a minimum acceptable level of statistical precision (SE of all attributes $<0.05$ ) when estimating preferences. To allow us to explore variation by demographic subgroups with precise statistical analysis, we obtained a sample of 1004 respondents.

Informed consent was obtained from all respondents via an online consent form prior to commencing the survey.

\section{Study design}

Following good research practice recommendations, we designed a DCE survey to elicit preferences and estimate the value of GEP testing information in treatment decisions for early-stage breast cancer in terms of personal utility. ${ }^{27} 29$ DCEs use robust quantitative methods grounded in economic theory to estimate the utility (value) of alternative choices involving hypothetical risk-benefit trade-offs for specific attributes; the higher the utility, the greater the value of the attribute in the decision.

The development of key attributes and levels was informed by a literature review and qualitative research. We conducted focus groups and interviews (in English), details reported elsewhere, ${ }^{17} 3637$ with $\mathrm{n}=28$ women with a history of breast cancer, ${ }^{36}$ interviews with $n=14$ oncologists. ${ }^{17} 37$ We also consulted the medical oncologists on our study team (MT, NL). Through this process, we identified themes that led to the development of five key attributes (each with three to four levels). The medical oncologists on our study team confirmed the clinical face validity of the proposed attributes and levels. The survey and DCE were then pretested in a sample of women from our focus groups $(n=3)$ and in a convenience sample from the general population $(n=11)$ using interviews and cognitive testing (one-on-one 'think aloud' methods). Pretesting was done to test understanding of survey content and obtain feedback on survey questions; preferences were not collected during survey pretesting. On the basis of pretesting feedback, we changed and simplified some of the terminology and wording of the background information, survey questions, attributes and levels. The updated survey was pilot tested in an online sample of $n=55$ women from the general population. Pilot testing was conducted to test online survey programming, duration to complete the survey, ensure respondents were able to complete the survey online and that there were no questions where dropouts were consistently occurring. Minor changes 
were made based on pilot test findings. The final attributes and levels used in the survey are presented in table 1 . The final survey was translated into French and reviewed by French-language speakers to ensure the translation was correct. The final survey consisted of four main parts: (1) experiences with cancer, breast cancer and chemotherapy; (2) background information discussing breast cancer, chemotherapy and GEP (how GEP works and how to interpret results; figures 1, 2 and 3); (3) the DCE (figure 4 and table 1) and (4) demographics. The survey was administered in both French and English.

We used Sawtooth Software SSI Web V.7.0.26 to create 50 survey versions with 12 choice tasks (10 random, 2 fixed) (Sawtooth Software SSI Web v. 7.0.26 [ program]. v. 7.0.26 version. Orem, UT: Sawtooth Software Inc., 2011). We generated the choice task experimental design using the balanced overlap method to permit estimation of main effects and interactions, and D-optimal procedures to maximise statistical efficiency (Sawtooth Software Inc, 2011). ${ }^{38}$ Since our sample size for the pilot test was small, we did not use the priors as a basis to inform the experimental design of the final survey. For each choice task, the respondent was asked to choose one situation out of three alternatives in which they would most likely select chemotherapy. Subsequently, to assess whether the alternatives were considered as realistic choices, there was an opt-out question in conjunction with each choice task where they were asked to indicate if they would actually choose chemotherapy if that was really their situation (figure 4).

\section{Statistical analysis}

Descriptive statistics (means for continuous variables, percentages for categorical variables) were used to examine the demographic and breast cancer experience variables. There were no missing data.

Hierarchical Bayes (HB) methods were used in the final analysis to estimate the part-worth utility of each attribute for individual survey respondents. HB was used because it provides part-worth utility coefficients for each respondent and greatly reduces the independence from irrelevant alternatives phenomenon inherent in the multinomial logit. HB uses the Markov chain Monte Carlo iterative algorithm to estimate individual respondent coefficients at the lower level of the hierarchical model using a multinomial logit algorithm and then a sharing of information among respondents at the higher level using a multivariate normal algorithm. The $\mathrm{HB}$ algorithm was set to run through 10000 iterations during the burn-in phase and 20000 iterations during the estimation period. The attribute part-worth utility coefficients were rescaled to be zero centred, with higher values denoting stronger preferences. We used $\chi^{2}$ tests to determine if choice patterns deviated from uniform and paired $\mathrm{t}$ tests to determine if the mean part-worth utilities were different within attributes. The

Table 1 Attributes and levels used in the discrete choice experiment

Attribute
1. Your doctor's estimate of risk of cancer returning
(without using a GEP test)

(without using a GEP test)

\section{Trust in your cancer treatment doctor}

3. Likelihood of temporary side effects (may commonly occur during chemotherapy-may include nausea, vomiting, numbness or tingling in fingers, hair loss, fever and infection) 4. Likelihood of permanent side effects (may occur after chemotherapy and last permanently-may include leukaemia (blood cancer), damage to the heart muscle and early menopause)

5. GEP test score

Likely benefit from chemotherapy

\section{Levels}

Low risk of cancer returning (eg, lymph node negative, the cancer is not responsive to Herceptin, the cancer is highly responsive to hormone therapy, tumour size is between 1.1 and $2.0 \mathrm{~cm}$ )

Intermediate risk of cancer returning (eg, lymph node negative, the cancer is not responsive to Herceptin, the cancer is less responsive to hormone therapy, tumour size is between 2.1 and $3 \mathrm{~cm}$ )

High risk of cancer returning (eg, lymph node negative, the cancer is responsive to Herceptin, the cancer is less responsive to hormone therapy, tumour size is between 3.1 and $5 \mathrm{~cm}$ )

Do not trust

Somewhat trust

Totally trust

Low

Moderate

High

Low

Moderate

High

9, Low benefit

22, Uncertain benefit

44, High benefit

GEP test not available

GEP, gene expression profiling. 
Figure 1 Breast cancer background information that was presented to respondents prior to completing the discrete choice experiment section of the survey. HER2, human epidermal growth factor receptor 2 .

\begin{tabular}{|c|c|c|}
\hline Cancer stage & Hormone Receptor Status & HER2 Status \\
\hline $\begin{array}{l}\text { Staging describes the severity of a } \\
\text { person's cancer. Knowing the stage } \\
\text { of disease helps the doctor plan } \\
\text { treatment and estimates the } \\
\text { chance cancer will return. } \\
\text { For early-stage breast cancer, } \\
\text { doctors typically look at the } \\
\text { following factors to determine the } \\
\text { extent or severity of a person's } \\
\text { cancer: } \\
\text { a. Categories of tumour size: } \\
-\quad 0.1-1 \mathrm{~cm} \\
-\quad 1.1-2 \mathrm{~cm} \\
-\quad 2.1-3 \mathrm{~cm} \\
-\quad 3.1-5 \mathrm{~cm} \\
\text { b } \quad \text { Greater than } 5 \mathrm{~cm} \\
\text { has spread into lymph nodes }\end{array}$ & $\begin{array}{l}\text { Hormone receptor status describes } \\
\text { how the cancer would respond to } \\
\text { hormone therapy. Hormone } \\
\text { receptor status typically ranges as } \\
\text { follows: } \\
\text { 1. The cancer is highly responsive to } \\
\text { hormone therapy } \\
\text { 2. The cancer is less responsive to } \\
\text { hormone therapy } \\
\text { 3. The cancer is not responsive to } \\
\text { hormone therapy }\end{array}$ & $\begin{array}{l}\text { HER2 status describes how the } \\
\text { cancer responds to Herceptin } \\
\text { treatment (drug used to treat } \\
\text { breast cancer that is HER2 positive). } \\
\text { HER2 status typically ranges as } \\
\text { follows: } \\
\text { 1. The cancer is responsive to } \\
\text { Herceptin } \\
\text { 2. The cancer is not responsive to } \\
\text { Herceptin }\end{array}$ \\
\hline
\end{tabular}

Brown-Forsythe test was used to test for statistically significant differences in part-worth utilities for multilevel covariates and $\mathrm{t}$ values were used for bilevel covariates. p Values $<0.05$ were considered statistically significant.

We used simulations and sensitivity analyses to estimate the relative influence of the five attributes, and various combinations of the attributes, on the likelihood of choosing chemotherapy treatment in alternative scenarios. The option to opt out of choosing chemotherapy is embedded within the simulation and sensitivity analyses.

\section{RESULTS}

A total of 1004 respondents completed the survey. The mean age of respondents was 49 years (median, 51 years; table 2). Two-thirds of respondents $(n=637)$ had at least some postsecondary education, over half $(n=580)$ were employed, $67 \%$ were married or living common-law,
$67 \%$ were without children, $42 \%$ were middle income (\$20 000-79 999) and 84\% were white (table 2). Overall, our sample is older and more educated than reports by Statistics Canada. ${ }^{39-43}$

More than $75 \%$ of respondents know someone who had chemotherapy for cancer but fewer than $40 \%$ reported they had cared for someone with cancer (table 2). Approximately half of respondents know of a relative who had/has breast cancer and more than $70 \%$ know someone other than a relative who had/has breast cancer. Only 5\% know someone who had GEP testing for breast cancer (table 2).

On average, $85 \%$ of respondents confirmed their choice about chemotherapy in the survey choice tasks based on their responses to the opt-out question about having chemotherapy, indicating that the choices presented in the survey were realistic and meaningful to the respondents. The part-worth utilities for attribute levels

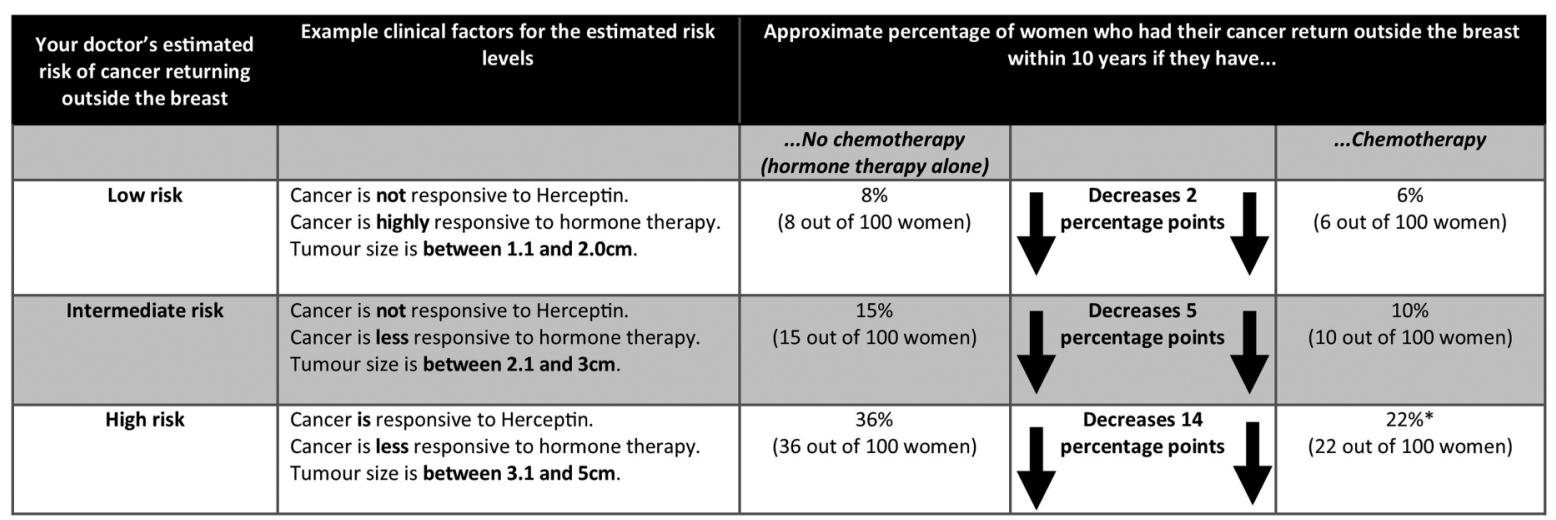

* Women in this category have HER2 positive breast cancer. HER2 positive breast cancer benefits from the drug Herceptin [pop-up: "Drug used to treat breast cancer that is HER2 positive"] in addition to chemotherapy.

Figure 2 'Your doctor's estimated risk of recurrence' attribute background information that was presented to respondents prior to completing the discrete choice experiment section of the survey. HER2, human epidermal growth factor receptor 2. 


\begin{tabular}{|c|c|c|c|c|}
\hline $\begin{array}{l}\text { GEP test score } \\
(0-100)\end{array}$ & \multicolumn{3}{|c|}{$\begin{array}{l}\text { Estimated risk of cancer returning outside the breast within } 10 \text { years if } \\
\text { they have... } \\
\text { (approximate percentage) }\end{array}$} & $\begin{array}{l}\text { Likely benefit } \\
\text { from } \\
\text { chemotherapy }\end{array}$ \\
\hline & ...No chemotherapy & & ...Chemotherapy & \\
\hline $\begin{array}{c}\text { Low risk } \\
\text { (score less than 18) }\end{array}$ & $\begin{array}{c}7 \% \\
\text { (7 out of } 100 \text { women) }\end{array}$ & $\begin{array}{c}\text { Decreases } 2 \\
\text { percentage point }\end{array}$ & $\begin{array}{c}5 \% \\
\text { (5 out of } 100 \text { women) }\end{array}$ & Low benefit \\
\hline $\begin{array}{l}\text { Intermediate risk } \\
\text { (score of } 18 \text { to less } \\
\text { than } 30 \text { ) }\end{array}$ & $\begin{array}{c}14 \% \\
\text { (14 out of } 100 \text { women) }\end{array}$ & $\begin{array}{c}\text { Decreases } 3 \\
\text { percentage point }\end{array}$ & $\begin{array}{c}11 \% \\
\text { (11 out of } 100 \text { women) }\end{array}$ & $\begin{array}{l}\text { Uncertain } \\
\text { benefit }\end{array}$ \\
\hline $\begin{array}{c}\text { High risk } \\
\text { (score of } 30 \text { to } 100)\end{array}$ & $\begin{array}{c}31 \% \\
\text { (31 out of } 100 \text { women) }\end{array}$ & $\begin{array}{c}\text { Decreases } 16 \\
\text { percentage point }\end{array}$ & $\begin{array}{c}15 \% \\
\text { (15 out of } 100 \text { women) }\end{array}$ & High benefit \\
\hline
\end{tabular}

Figure 3 'GEP test score and likely benefit from chemotherapy' attribute background information that was presented to respondents prior to completing the discrete choice experiment section of the survey. GEP, gene expression profiling.

are plotted in figure 5. The GEP test score and likely benefit from chemotherapy attribute has the greatest utility relative to the remaining attributes-doctor's estimate of the risk of cancer returning (without using a GEP test), trust in your cancer doctor and likelihood of side effects (temporary and permanent).

The part-worth utility estimates of GEP test scores were in line with expectations, with a low GEP score of 9 having the lowest (and negative) part-worth utility (and associated with a low likelihood of choosing chemotherapy) and a high GEP score of 44 having the highest partworth utility (and a high likelihood of choosing chemotherapy) (table 3). The part-worth utilities of the GEP test not being available and the GEP score being uncertain are similar and it is likely that neither influences the decision to choose chemotherapy.

Likelihood of permanent side effects was next most influential on respondents' likelihoods of choosing chemotherapy; a treatment having a higher likelihood of permanent side effects would lower the likelihood of the respondent choosing chemotherapy. The doctor's estimate of risk of cancer returning (without using a GEP test) also strongly influenced chemotherapy decisions of respondents and demonstrated a monotonically increasing effect as the doctor's estimate of risk increased from low to intermediate and then to high risk. The effects were well spaced and were statistically different $(\mathrm{p}<0.001)$. Trust in your cancer treatment doctor followed a similar pattern as

If you had early-stage breast cancer, under which of the following scenarios would you be most likely to choose chemotherapy, if you were to have chemotherapy?

\begin{tabular}{|c|c|c|c|}
\hline \multicolumn{4}{|c|}{ Choose by clicking one of the buttons below: } \\
\hline $\begin{array}{r}\text { Your doctor's estimate of risk of } \\
\text { cancer returning (without using a } \\
\text { GEP test) }\end{array}$ & $\frac{\text { High risk of cancer }}{\text { returning }}$ & $\frac{\text { Low risk of cancer }}{\text { returning }}$ & $\frac{\text { Intermediate risk of }}{\text { cancer returning }}$ \\
\hline Likelihood of temporary side effects & Moderate & Moderate & High \\
\hline Likelihood of permanent side & High & Moderate & Low \\
\hline $\begin{array}{r}\text { Trust in your cancer treatment } \\
\text { doctor }\end{array}$ & Moderately trust & Totally trust & Slightly trust \\
\hline $\begin{array}{r}\text { GEP test score } \\
\text { Likely benefit from chemotherapy }\end{array}$ & GEP test not available & $\begin{array}{l}22 \\
\text { Uncertain benefit }\end{array}$ & $\begin{array}{l}44 \\
\text { High benefit }\end{array}$ \\
\hline & 0 & 0 & 0 \\
\hline
\end{tabular}

Now, if you had the choice to have chemotherapy, and if the scenario you chose above was really your situation, what would you do?

I would still have chemotherapy

I would not have chemotherapy

Figure 4 A sample choice task from the discrete choice experiment survey examining chemotherapy treatment decisions for early-stage breast cancer in the sample of $n=1004$ women from the general population. GEP, gene expression profiling. 
Table 2 Demographics and cancer experiences of respondents ( $n=1004,5$ of which were in French)

\begin{tabular}{|c|c|c|}
\hline Variable & $\mathbf{n}$ & $\begin{array}{l}\text { Per } \\
\text { cent }\end{array}$ \\
\hline Average age & 1004 & 49 years \\
\hline \multicolumn{3}{|l|}{ Education } \\
\hline $\begin{array}{l}\text { Less than high school/high school } \\
\text { diploma }\end{array}$ & 367 & 37 \\
\hline $\begin{array}{l}\text { Apprenticeship or college diploma(s)/ } \\
\text { some university }\end{array}$ & 358 & 36 \\
\hline University degree(s) & 279 & 28 \\
\hline \multicolumn{3}{|l|}{ Employment status (current paid work) } \\
\hline $\begin{array}{l}\text { Yes (outside the home and } \\
\text { self-employed) }\end{array}$ & 580 & 58 \\
\hline No (unemployed, retired, other) & 424 & 42 \\
\hline \multicolumn{3}{|l|}{ Population centre } \\
\hline Small population centre (<29 999) & 230 & 23 \\
\hline $\begin{array}{l}\text { Medium population centre } \\
(30000-99 \text { 999) }\end{array}$ & 187 & 19 \\
\hline $\begin{array}{l}\text { Large urban population centre } \\
(\geq 100000)\end{array}$ & 587 & 58 \\
\hline \multicolumn{3}{|l|}{ Marital status } \\
\hline Married/living common-law & 675 & 67 \\
\hline Widowed/separated/divorced/single & 329 & 33 \\
\hline \multicolumn{3}{|l|}{ Children living at home } \\
\hline Yes, with children & 335 & 33 \\
\hline \multicolumn{3}{|l|}{ Race* $^{*}$} \\
\hline White & 841 & 84 \\
\hline First Nations, Metis or Inuit & 19 & 2 \\
\hline Chinese & 61 & 6 \\
\hline Black & 7 & 1 \\
\hline All other & 54 & 5 \\
\hline \multicolumn{3}{|l|}{2011 Household income* } \\
\hline$<\$ 19999$ & 36 & 4 \\
\hline$\$ 20000-79999$ & 421 & 42 \\
\hline$\geq \$ 80000$ & 348 & 35 \\
\hline \multicolumn{3}{|l|}{ Cancer experiences } \\
\hline $\begin{array}{l}\text { Know someone who had chemotherapy } \\
\text { for cancer }\end{array}$ & 791 & 79 \\
\hline Cared for someone else with cancer & 348 & 35 \\
\hline $\begin{array}{l}\text { Know of a relative(s) who has, or had, } \\
\text { breast cancer }\end{array}$ & 489 & 49 \\
\hline $\begin{array}{l}\text { Know someone other than a relative } \\
\text { who has, or had, breast cancer }\end{array}$ & 740 & 74 \\
\hline $\begin{array}{l}\text { Know someone who had GEP testing } \\
\text { for breast cancer }\end{array}$ & 51 & 5 \\
\hline
\end{tabular}

the doctor's estimate of risk of cancer returning. The likelihood of temporary side effects was least influential in the chemotherapy decision.

The simulation examines three profiles with trust in the cancer treatment doctor and likelihood of temporary and permanent side effects held constant at the moderate level in all profiles:

- High-risk profile-the doctor's estimate of risk of cancer returning (without a GEP test) is high and the GEP test score and likely benefit from chemotherapy was also high (44).
- Moderate-risk profile-the doctor's estimate of risk of cancer returning (without using GEP) was intermediate and the GEP test score and likely benefit from chemotherapy was uncertain (22).

- Low-risk profile-the doctor's estimate of risk of cancer returning (without using GEP) was low and the GEP test score and likely benefit from chemotherapy was low (9).

The simulation estimates that $78 \%$ would choose chemotherapy in the high-risk profile, whereas only $55 \%$ would choose chemotherapy in the moderate-risk profile and $33 \%$ in the low-risk profile (figure 6).

The graphs summarising likelihood of choosing chemotherapy were similarly shaped, but of different levels of magnitude, among the three levels for the doctor's estimate of risk (figure 6). In each scenario, the lowest likelihood of choosing chemotherapy was for the lowest GEP score of 9. The likelihoods were similar between the 'GEP tests not available' and '22, uncertain benefit' levels over the three doctor's estimate of risk levels. As expected, the highest likelihoods of choosing chemotherapy occurred when the GEP score was 44. While the likelihoods increased with the level of clinical risk when the GEP test score was 44, the likelihood for high clinical risk was similar to intermediate clinical risk (77.9 vs 77.7). This suggests that the GEP score has more weight at the high GEP score level for those at intermediate clinical risk.

The part-worth utilities were significantly different in only a few of the attribute levels when split by several covariates (online supplementary appendix table S1). There were no statistically significant differences for employment, province of residence, age or language. There were only a few statistically significant differences for 'know someone who has/had breast cancer', income, 'relative who has/had breast cancer', marital status and whether there were 'children in the household' with no particular pattern overall (online supplementary appendix table $\mathrm{S} 1$ ).

\section{DISCUSSION}

Treatment of patients when the likelihood of benefit is low and there is a risk of side effects can cause harm and also generate unnecessary costs to the healthcare system. ${ }^{78}$ Concerns about overtreatment have grown as less severe forms of disease are treated and treatment benefits are overestimated. ${ }^{9}$ GEP is a form of personalised medicine that can help inform effective treatment decisions. We estimated the value of GEP in chemotherapy treatment decision-making for early-stage breast cancer in the context of benefit-risk trade-offs. We found that GEP is highly valued and strongly influences chemotherapy treatment decisions in a sample of women from the general population.

The strengths of our study are fourfold. To our knowledge, this is the first utility-based survey to obtain quantitative benefit-risk data on the value of GEP testing in 


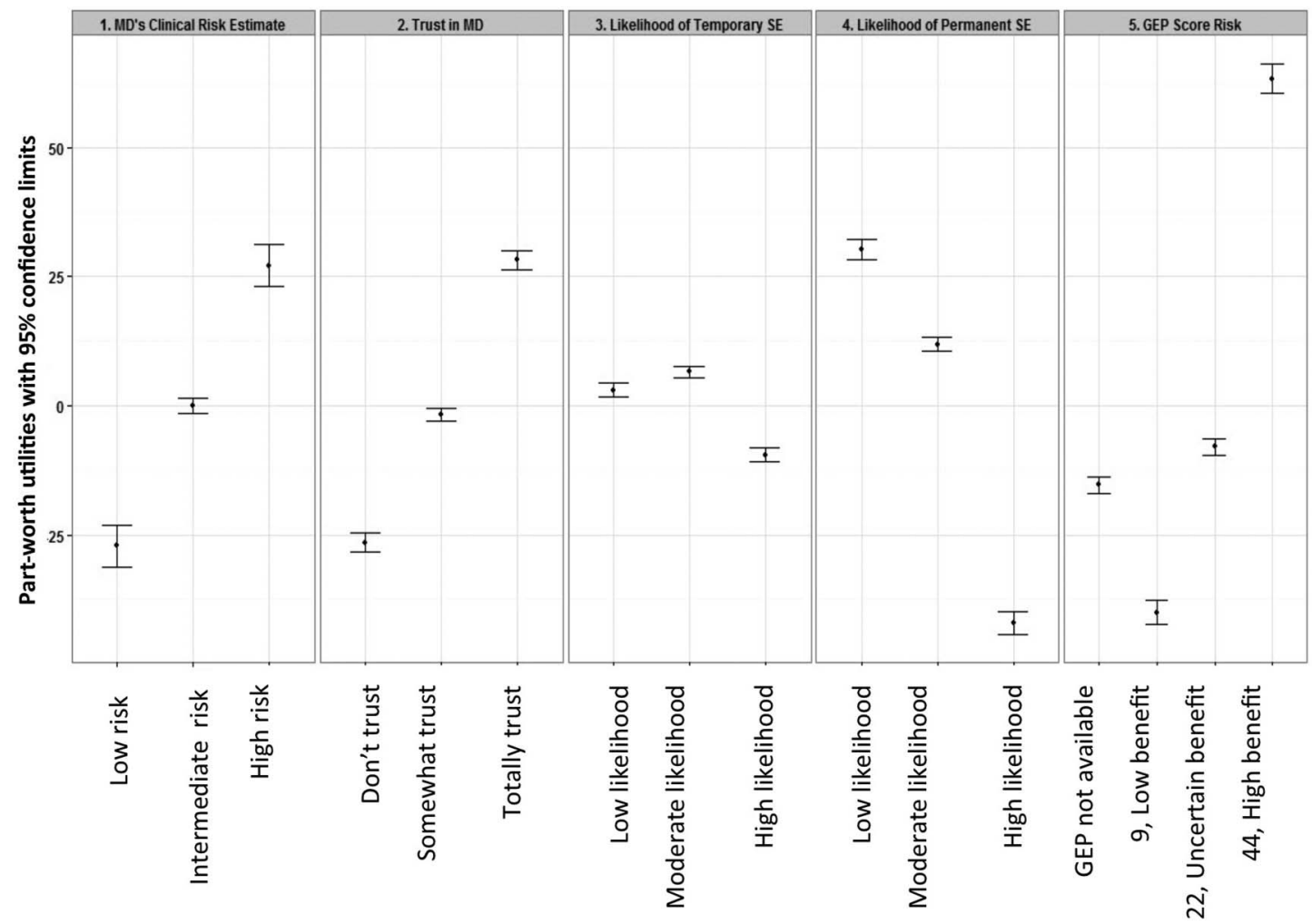

Attributes and Levels

Figure 5 The part-worth utilities of the levels for each attribute (with 95\% confidence limits), representing the relative influence of each on the choice of undergoing chemotherapy for early-stage breast cancer in the sample of $n=1004$ women from the general population. GEP, gene expression profiling; SE, side effects; MD, cancer treatment doctor.

breast cancer treatment decisions. Second, the hypothetical choice tasks had high face validity, demonstrated by the directionality, magnitude and consistency of responses, and the high rate of confirmation about chemotherapy decisions. Third, we had a large sample of women from the general population who may be at risk of breast cancer and are major stakeholders in a publicly funded healthcare system, although they were older and more educated. Individuals who are more educated may be more interested in receiving GEP information and older individuals may be inclined to more heavily weighted decisions based on doctor's estimate of risk. Last, our results can be generalised to the female population at risk of breast cancer in Canada who may ultimately face a decision about GEP.

Our study had some limitations. There is the possibility of incentive bias when using an online survey panel. However, this method and the use of incentives are common, and research exploring online surveys has demonstrated validity and reliability that is comparable to traditional methods. ${ }^{44}{ }^{45}$ Second, the choice tasks were hypothetical scenarios and respondents' choices may be different when faced with these decisions in real life. Last, the information provided within the survey was comprehensive and complex, which required a high level of understanding to complete the survey. It is possible that some respondents did not fully understand the survey. However, our pretesting confirmed that respondents were understanding the survey. Additionally, based on our analysis of the DCE opt-out question that asks if they would actually choose chemotherapy if that was really their situation, it would appear that the choice tasks were realistic and meaningful to respondents. However, it is well known that risk is complex to communicate. ${ }^{46}{ }^{47}$ In this era of complexity of clinical decision-making that is introduced by GEP and other types of testing for personalised medicine, it is challenging for clinicians to communicate this information to patients. There may be an increased role for decision aids eliciting patient preferences and communicating risk to inform personalised treatment decisions.

GEP testing information has significant influence on the potential stated uptake of chemotherapy treatment but varies depending on clinical risk. Recent findings from the TAILORx trial reported that about $16 \%$ of women with breast cancer who met established guidelines for adjuvant chemotherapy based on clinicopathologic features had a recurrence score of 10 or lower (low risk) and had very low rates of recurrence at 5 years with endocrine therapy alone. ${ }^{48}$ This is a group of women who could potentially be 'restratified' to no chemotherapy treatment based on GEP results. Our simulations of 
Table 3 Mean part-worth utility values (rescaled as zero centred) for the $n=1004$ respondents

\begin{tabular}{|c|c|c|c|c|}
\hline Attributes and levels & $\begin{array}{l}\text { Mean } \\
\text { part-worth } \\
\text { utility }\end{array}$ & SE & t Values & $\begin{array}{l}\text { Mean } \\
\text { significantly } \\
\text { different from } 0\end{array}$ \\
\hline \multicolumn{5}{|l|}{ MD's clinical risk estimate } \\
\hline Low risk & -29.81 & 2.55 & -11.68 & 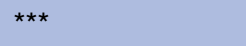 \\
\hline Intermediate risk & 0.20 & 0.89 & 0.22 & NS \\
\hline High risk & 29.61 & 2.48 & 11.95 & $* * *$ \\
\hline \multicolumn{5}{|l|}{ Trust in MD } \\
\hline Do not trust & -25.54 & 0.98 & -26.10 & 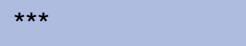 \\
\hline Somewhat trust & -0.73 & 0.67 & -1.09 & NS \\
\hline Totally trust & 26.27 & 0.92 & 28.55 & $\star \star \star$ \\
\hline \multicolumn{5}{|l|}{ Likelihood of temporary SE } \\
\hline Low likelihood & 2.47 & 0.75 & 3.27 & ** \\
\hline Moderate likelihood & 7.55 & 0.60 & 12.60 & $* \star *$ \\
\hline High likelihood & -10.02 & 0.75 & -13.34 & $\star \star \star *$ \\
\hline \multicolumn{5}{|l|}{ Likelihood of permanent SE } \\
\hline Low likelihood & 33.75 & 1.10 & 30.59 & $* \star *$ \\
\hline Moderate likelihood & 12.25 & 0.76 & 16.13 & $* \star *$ \\
\hline High likelihood & -46.00 & 1.22 & -37.66 & 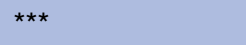 \\
\hline \multicolumn{5}{|l|}{ GEP score, likely benefit from chemotherapy } \\
\hline GEP not available & -17.34 & 0.86 & -20.18 & $* * *$ \\
\hline 9, Low benefit & -43.39 & 1.21 & -35.73 & 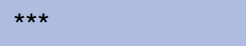 \\
\hline 22, Uncertain benefit & -6.83 & 0.89 & -7.65 & 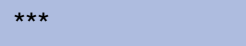 \\
\hline 44, High benefit & 67.56 & 1.52 & 44.48 & $* * *$ \\
\hline $\begin{array}{l}\text { General preference for chemotherapy } \\
\text { vs no chemotherapy }\end{array}$ & -49.53 & 5.74 & -8.63 & *** \\
\hline
\end{tabular}

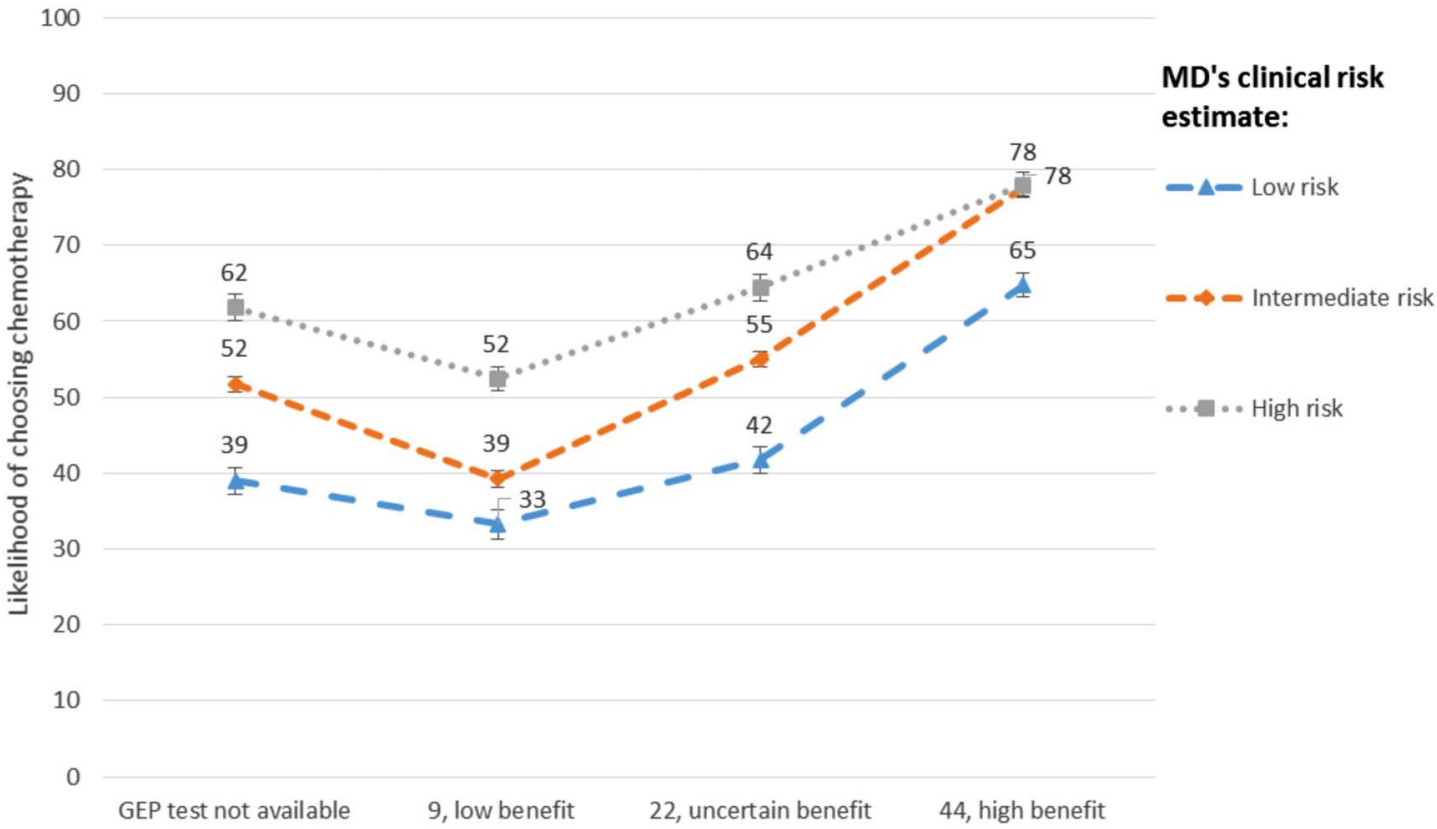

GEP test score and likely benefit from chemotherapy

Figure 6 Likelihood of choosing chemotherapy for early-stage breast cancer under different doctor's estimate of risk and GEP test score simulation scenarios in the sample of $n=1004$ women from the general population. All other attribute levels were held constant (trust in cancer treatment doctor=somewhat trust, and both likelihood of temporary and permanent side effects=moderate). GEP, gene expression profiling; SE, side effects; MD, cancer treatment doctor. 
preferences examining the influence of GEP test scores on the likelihood of choosing chemotherapy suggest that GEP testing had the greatest influence for those at intermediate clinical risk. For example, a high GEP score would increase the likelihood of choosing chemotherapy from $55 \%$ to $78 \%$, and a low GEP score would decrease the likelihood of choosing chemotherapy from $55 \%$ to $39 \%$. From a population perspective, this 'restratification' of patients could reduce uncertainty for patients with intermediate risk and could reduce the use of adjuvant chemotherapy, side effects and the associated costs for some patients who would likely not benefit from treatment, as has been observed in a recent retrospective cohort study. ${ }^{49}$

Public and patient preferences have implications for the use of personalised medicine in clinical practice; personalised medicine tests are more likely to be adopted if they are valued by patients, the public and physicians. The findings from our study of public preferences are consistent with studies that have examined patient attitudes towards GEP testing. Bombard $e t a l^{36}$ found that patients valued GEP because it provided them with certainty amidst confusion, with options and a sense of empowerment and with personalized, authoritative information'. In a study of patients with breast cancer, GEP testing is found to be acceptable and more than $60 \%$ indicated that the main reason for undergoing GEP testing was to 'access the most appropriate treatment'. ${ }^{50}$ Many studies have also found that GEP influences or changes chemotherapy treatment decisions. ${ }^{18-26}$ Furthermore, patients with cancer are willing to pay increasing amounts to avoid chemotherapy side effects. $^{51}$

Health policymakers require evidence that demonstrates the value of GEP to support policy decisions regarding funding and reimbursement, and are increasingly incorporating public values into these decisions. ${ }^{32}$ We found that GEP is highly valued and strongly influences chemotherapy treatment decisions in a sample of women from the general population but varies depending on clinical risk. Specific individuals may be more or less likely to change their chemotherapy treatment decisions. Clinicians should be aware of these differences and consider the use of GEP testing accordingly. Future research should examine preferences and the value of GEP in different population groups, such as patients with breast cancer, medical oncologists and subgroups of these populations who may have different preferences, to understand heterogeneity within these populations.

\footnotetext{
Author affiliations

${ }^{1}$ Department of Community Health Sciences, University of Calgary, Calgary, Alberta, Canada

${ }^{2}$ DeGroote School of Business, McMaster University, Hamilton, Ontario, Canada

${ }^{3} \mathrm{Li}$ Ka Shing Knowledge Institute of St. Michael's Hospital, Toronto, Ontario, Canada

${ }^{4}$ Institute of Health Policy, Management and Evaluation, University of Toronto, Toronto, Ontario, Canada
}

${ }^{5}$ Department of Medicine, University of Toronto, Toronto, Ontario, Canada

${ }^{6}$ Princess Margaret Cancer Centre, Toronto, Ontario, Canada

${ }^{7}$ University of Toronto, Toronto, Ontario, Canada

${ }^{8}$ Sunnybrook Health Sciences Centre, Toronto, Ontario, Canada

Acknowledgements The authors thank all of the respondents for their time and participation in the study.

Contributors DAM led the conception and design of the work, drafting and critical revision of the manuscript and contributed to the statistical analysis and interpretation of data. KD led the statistical analysis and interpretation of data and contributed to the conception and design of the work, drafting and critical revision of the manuscript. YB and NL contributed to the conception and design of the work, interpretation of data and critical revision of the manuscript. KVM contributed to the acquisition, analysis and interpretation of data, literature review, drafting and critical revision of the manuscript. MT contributed to the conception and design of the work, interpretation of data and critical revision of the manuscript. All authors have approved the final version of the article submitted and agree to be accountable for all aspects of the work.

Funding This study was funded by grants from the Ontario Institute for Cancer Research/Cancer Care Ontario and the Canadian Centre for Applied Research in Cancer Control. The Canadian Centre for Applied Research in Cancer Control is funded by the Canadian Cancer Society Research Institute. The study sponsor did not have a role in the study design; collection, analysis and interpretation of the data; in the writing of the manuscript; and in the decision to submit the manuscript for publication. DM is a Canada Research Chair in Health Systems and Services Research, and Arthur J.E. Child Chair in Rheumatology.

Competing interests DAM undertakes ad hoc consulting through Optum Insight, a global company, for various health economics and outcomes research projects outside of this work. MT declares funding from Genomic Health outside of this work. All other authors have nothing to declare. ICMJE author conflict of interest forms are available for each author upon request.

Ethics approval St. Joseph's Healthcare Hamilton, McMaster University and the Hamilton Integrated Research Ethics Board.

Provenance and peer review Not commissioned; externally peer reviewed.

Data sharing statement No additional data are available.

Open Access This is an Open Access article distributed in accordance with the Creative Commons Attribution Non Commercial (CC BY-NC 4.0) license, which permits others to distribute, remix, adapt, build upon this work noncommercially, and license their derivative works on different terms, provided the original work is properly cited and the use is non-commercial. See: http:// creativecommons.org/licenses/by-nc/4.0/

\section{REFERENCES}

1. Canadian Cancer Society's Advisory Committee on Cancer Statistics. Canadian cancer statistics 2013. Toronto, ON: Canadian Cancer Society, 2013.

2. Radice D, Redaelli A. Breast cancer management: quality-of-life and cost considerations. Pharmacoeconomics 2003;21:383-96.

3. National Comprehensive Cancer Network. NCCN Clinical Practice Guidelines in Oncology: Breast Cancer V.1.2014. 2014. https://www. nccn.org/professionals/physician_gls/f_guidelines.asp\#site

4. Marchionni L, Wilson RF, Wolff AC, et al. Systematic review: gene expression profiling assays in early-stage breast cancer. Ann Intern Med 2008;148:358-69.

5. Persing M, Grosse R. Current St Gallen recommendations on primary therapy of early breast cancer. Breast Care 2007;2:137-40.

6. Marchionni L, Wilson RF, Marinopoulos SS, et al. Impact of gene expression profiling tests on breast cancer outcomes. Rockville, MD: Agency for Healthcare Research and Quality, 2008.

7. Heath I. Overdiagnosis: when good intentions meet vested interests —an essay by lona Heath. BMJ 2013;347:f6361.

8. The BMJ. Too Much Medicine. 2014. http://www.bmj.com/ too-much-medicine

9. Moynihan R, Doust J, Henry D. Preventing overdiagnosis: how to stop harming the healthy. BMJ 2012;344:e3502.

10. Heath I. Role of fear in overdiagnosis and overtreatment-an essay by lona Heath. BMJ 2014;349:g6123. 
11. Buyse M, Loi S, van't Veer L, et al., TRANSBIG Consortium. Validation and clinical utility of a 70-gene prognostic signature for women with node-negative breast cancer. $J$ Natl Cancer Inst 2006:98:1183-92.

12. Paik S, Shak S, Tang G, et al. A multigene assay to predict recurrence of tamoxifen-treated, node-negative breast cancer. N Engl J Med 2004;351:2817-26.

13. Mina L, Soule SE, Badve S, et al. Predicting response to primary chemotherapy: gene expression profiling of paraffin-embedded core biopsy tissue. Breast Cancer Res Treat 2007;103:197-208.

14. Ma XJ, Hilsenbeck SG, Wang W, et al. The HOXB13:IL17BR expression index is a prognostic factor in early-stage breast cancer. $J$ Clin Oncol 2006;24:4611-19.

15. van de Vijver MJ, He YD, van 't Veer LJ, et al. A gene-expression signature as a predictor of survival in breast cancer. N Engl J Med 2002;347:1999-2009.

16. Cianfrocca M, Goldstein LJ. Prognostic and predictive factors in early-stage breast cancer. Oncologist 2004;9:606-16.

17. Bombard $\mathrm{Y}$, Rozmovits $\mathrm{L}$, Trudeau $\mathrm{M}$, et al. The value of personalizing medicine: medical oncologists' views on gene expression profiling in breast cancer treatment. Oncologist 2015;20:351-6.

18. Albanell J, González A, Ruiz-Borrego M, et al. Prospective transGEICAM study of the impact of the 21-gene Recurrence Score assay and traditional clinicopathological factors on adjuvant clinical decision making in women with estrogen receptor-positive (ER+) node-negative breast cancer. Ann Oncol 2012;23:625-31.

19. Asad J, Jacobson AF, Estabrook A, et al. Does oncotype DX recurrence score affect the management of patients with early-stage breast cancer? Am J Surg 2008;196:527-9.

20. Geffen DB, Abu-Ghanem S, Sion-Vardy N, et al. The impact of the 21-gene recurrence score assay on decision making about adjuvant chemotherapy in early-stage estrogen-receptor-positive breast cancer in an oncology practice with a unified treatment policy. Ann Oncol 2011;22:2381-6.

21. Henry LR, Stojadinovic A, Swain SM, et al. The influence of a Gene expression profile on breast cancer decisions. J Surg Oncol 2009;99:319-23.

22. Partin JF, Mamounas EP. Impact of the 21-gene recurrence score assay compared with standard clinicopathologic guidelines in adjuvant therapy selection for node-negative, estrogen receptor-positive breast cancer. Ann Surg Oncol 2011:18:3399-406.

23. Oratz R, Paul D, Cohn AL, et al. Impact of a commercial reference laboratory test recurrence score on decision making in early-stage breast cancer. J Oncol Pract 2007;3:182-6.

24. Biroschak JR, Schwartz GF, Palazzo JP, et al. Impact of Oncotype $\mathrm{DX}$ on treatment decisions in ER-positive, node-negative breast cancer with histologic correlation. Breast J 2013;19:269-75.

25. DeFrank JT, Carey LA, Brewer NT. Understanding how breast cancer patients use risk information from genomic tests. J Behav Med 2013;36:567-73.

26. Levine MN, Julian JA, Bedard PL, et al. Prospective Evaluation of the 21-Gene Recurrence Score Assay for Breast Cancer Decision-Making in Ontario. J Clin Oncol 2016;34:1065-71.

27. Phillips KA, Johnson FR, Maddala T. Measuring what people value: a comparison of "attitude" and "preference" surveys. Health Serv Res 2002;37:1659-79.

28. Feero WG, Wicklund C, Veenstra DL. The economics of genomic medicine: insights from the IOM roundtable on translating genomic-based research for health. JAMA 2013;309:1235-6.

29. Bridges JF, Hauber AB, Marshall D, et al. Conjoint analysis applications in health-a checklist: a report of the ISPOR Good Research Practices for Conjoint Analysis Task Force. Value Health 2011:14:403-13.

30. Grosse SD, McBride CM, Evans JP, et al. Personal utility and genomic information: look before you leap. Genet Med 2009;11:575-6.
31. Patient preference information-submission, review in PMAs, HDE applications, and De Novo requests, and inclusion in device labeling. Rockville, MD: U.S. Department of Health and Human Services Food and Drug Administration, 2015.

32. Bombard Y, Abelson J, Simeonov D, et al. Eliciting ethical and social values in health technology assessment: a participatory approach. Soc Sci Med 2011;73:135-44.

33. e-Rewards Market Research. e-Rewards Answers ESOMAR's 26 Questions to Help Research Buyers. 2008.

34. Orme BK. Getting started with conjoint analysis: strategies for product design and pricing research. Madison, WI: Research Publishers, 2006.

35. Hensher DA, Rose JM, Greene WH. Applied choice analysis: a primer. Cambridge, UK: Cambridge University Press, 2005.

36. Bombard Y, Rozmovits L, Trudeau ME, et al. Patients' perceptions of gene expression profiling in breast cancer treatment decisions. Curr Oncol 2014;21:e203-11.

37. Bombard Y, Rozmovits L, Trudeau M, et al. Access to personalized medicine: factors influencing the use and value of gene expression profiling in breast cancer treatment. Curr Oncol 2014;21: e426-33.

38. Reed Johnson R, Lancsar E, Marshall D, et al. Constructing experimental designs for discrete-choice experiments: report of the ISPOR Conjoint Analysis Experimental Design Good Research Practices Task Force. Value Health 2013;16:3-13.

39. Employment and Social Development Canada. Indicators of well-being in Canada. Financial Security-Family Income, 2011.

40. Employment and Social Development Canada. Indicators of well-being in Canada. Learning-Educational Attainment, 2012. http://www4.hrsdc.gc.ca/.3ndic.1t.4r@-eng.jsp?iid=29\#M_2.

41. Employment and Social Development Canada. Indicators of well-being in Canada. Work-Weekly Earnings, 2012. http://www4 hrsdc.gc.ca/.3ndic.1t.4r@-eng.jsp?iid=18

42. Statistics Canada. 2011 Census of Canada: topic-based tabulations. Age (131) and Sex (3) for the Population of Canada, Provinces, Territories, Census Divisions, Census Subdivisions and Dissemination Areas, 2011 Census. 2013. http://www12.statcan.gc. ca/census-recensement/2011/dp-pd/tbt-tt/Rp-eng.cfm? LANG $=E \& A P A T H=3 \& D E T A I L=0 \& D I M=0 \& F L=A \& F R E E=0 \& G C=$ $0 \& G I D=0 \& G K=0 \& G R P=1 \& P I D=101998 \& P R I D=0 \& P T Y P E=101955 \&$ $\mathrm{S}=0 \& \mathrm{SHOWALL}=0 \& \mathrm{SUB}=0 \&$ Temporal $=2011 \& \mathrm{THEME}=88 \&$ $\mathrm{VID}=0 \& \mathrm{VNAMEE}=\& \mathrm{VNAMEF}=$

43. Robles C, Milan A. Women in Canada: a gender-based statistical report. Ottawa: Statistics Canada, 2011.

44. Evans JR, Mathur A. The value of online surveys. Internet Res 2005;15:195-219.

45. Eysenbach $\mathrm{G}$, Wyatt J. Using the Internet for surveys and health research. J Med Internet Res 2002;4:E13.

46. Ahmed $\mathrm{H}$, Naik $\mathrm{G}$, Willoughby $\mathrm{H}$, et al. Communicating risk. $B M J$ 2012;344:e3996.

47. Fagerlin A, Zikmund-Fisher BJ, Ubel PA. Helping patients decide: ten steps to better risk communication. J Natl Cancer Inst 2011;103:1436-43.

48. Sparano JA, Gray RJ, Makower DF, et al. Prospective Validation of a 21-Gene Expression Assay in Breast Cancer. N Engl J Med 2015;373:2005-14.

49. Epstein AJ, Wong YN, Mitra N, et al. Adjuvant Chemotherapy Use and Health Care Costs After Introduction of Genomic Testing in Breast Cancer. J Clin Oncol 2015;33:4259-67.

50. Seror V, Marino P, Bertucci F, et al. Breast cancer patients' views on the use of genomic testing to guide decisions about their postoperative chemotherapy. Public Health Genomics 2013:16:110-17.

51. Miller PJ, Balu S, Buchner D, et al. Willingness to pay to prevent chemotherapy induced nausea and vomiting among patients with breast, lung, or colorectal cancer. J Med Econ 2013;16: 1179-89. 
Correction: How do women trade-off benefits and risks in chemotherapy treatment decisions based on gene expression profiling for early-stage breast cancer? A discrete choice experiment

Marshall DA, Deal K, Bombard Y, et al. How do women trade-off benefits and risks in chemotherapy treatment decisions based on gene expression profiling for early-stage breast cancer? A discrete choice experiment. BMJ Open 2016;6:e10981.

Table 2 title should read: 'Table 2 Demographics and cancer experiences of respondents $(\mathrm{n}=1004,21$ of which were French)'. This correction does not change the interpretation of results or the manuscript.

Open Access This is an Open Access article distributed in accordance with the Creative Commons Attribution Non Commercial (CC BY-NC 4.0) license, which permits others to distribute, remix, adapt, build upon this work noncommercially, and license their derivative works on different terms, provided the original work is properly cited and the use is non-commercial. See: http://creativecommons.org/licenses/by-nc/4.0/

BMJ Open 2016;6:e010981corr1. doi:10.1136/bmjopen-2015-010981corr1

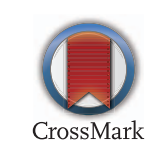

